\title{
PERGUNTA SE MACACO QUER BANANA! BREVE ANÁLISE DE FRÁSES FEITAS \\ JOCOSAS: ESTUDO DA LÍNGUA \\ EM USO COM O AUXÍLIO DA \\ LINGÜISTICA DE CORPUS
}

\begin{abstract}
Adauri Brezolin*
RESUMO: Embora tenha crescido o interesse pela fraseologia nos últimos anos, ainda resta muita pesquisa a ser feita sobre determinadas estruturas formulaicas, sobretudo em lingua portuguesa do Brasil. O presente artigo pretende, assim, fazer uma breve análise de um tipo bastante específico das fórmulas situacionais, a saber: as frases feitas jocosas (denominação proposta por nós). Nosso estudo, que parte de frases feitas jocosas coletadas de maneira intuitiva, discute a denominação proposta, analisa as frases feitas jocosas do ponto de vista pragmático e, ainda, verifica o tratamento dado a tais expressões em três importantes dicionários e dois corpora eletrônicos, todos em língua portuguesa. A Lingüística de Corpus foi empregada como aparato metodológico em nossa análise. Ao investigarmos importantes obras lexicográficas e corpora eletrônicos em português, percebemos que as frases feitas jocosas não aparecem ali; isso nos conduziu a pesquisá-las na internet. Dentre os vários tipos de sites, observamos que os blogs são os que mais contêm tais expressões. Nossa pesquisa demonstra, entre outras coisas, que a internet, principalmente os blogs, revelou-se como um grande repositório de frases feitas jocosas; que algumas das expressões em questão tampouco aparecem nessa grande rede; e que a grande maioria das expressões é de fato empregada pelos falantes. Além disso, algumas expressões nem sempre aparecem como as imaginamos, mas sim com variações em sua estrutura, o que nos leva a crer que não possuem um grau de fixidez tão elevado.
\end{abstract}

* Doutor em Letras (USP), docente no UNIBERO e na Universidade Metodista de São Paulo. 
UNITERMOS: expressões idiomáticas; fórmulas situacionais; frases feitas jocosas; Lingüística de Corpus; tradução.

ABSTRACT: Although the interest in phraseology has grown in recent years, a lot of research remains to be carried out on certain formulaic expressions, mainly in Brazilian Portuguese. This paper sets out to briefly investigate a very specific type of situational formulae, namely: stock conversational witticisms. This article focuses on a series of intuitively collected stock conversational witticisms in Brazilian Portuguese, discusses their classification, analyses them in their pragmatic function, and still, verifies how they are treated in three major dictionaries as well as in two computerized corpora, both in Portuguese, by using Corpus Linguistics as the main methodology. Our first analysis showed that such dictionaries and corpora do not include the stock conversational witticisms in question. This led us to investigate them on the Web. Among the various types of sites, most of the stock conversational witticisms were observed in blogs. Our findings reveal, among other things, that the Web, specially the blogs, seem to be a suitable and large repository of such expressions; that some of the phrases are not even on the Web; and that most of the expressions are indeed used by speakers. Besides, some of the expressions were found with variations in their structure, signaling that their level of fixedness is not as high as supposed.

KEYWORDS: idioms; situational formulae; stock conversational witticisms; Corpus Linguistics; translation.

\section{Introdução}

Na qualidade de professor de língua inglesa e de tradução, temos conhecimento da quantidade de expressões que tentamos entender, explicar e traduzir, e que, na maioria das vezes, são classificadas como expressões idiomáticas. No entanto, não nos parece justo tratar a ampla gama de expressões de maneira tão genérica. Assim, quando alguém oferece a resposta "Pergunta se macaco quer banana!", que figura no título deste artigo, ela não 
parece ser uma simples expressão idiomática. Acreditamos que haja muito mais a saber sobre suas características. Dentro deste vasto universo das expressões idiomáticas e convencionais, pretendemos analisar um tipo de fórmula situacional bastante específica: as frases feitas jocosas (denominação dada por nós e discutida mais adiante), entendidas, no presente trabalho, como fórmulas de efeito cômico, ou ligeiramente engraçadas, empregadas durante uma conversação para divertir ou criticar alguém.

Estudar tais fórmulas parece-nos bastante apropriado, uma vez que, por um lado, tem sido grande nas últimas décadas o interesse pela fraseologia (estruturas pré-fabricadas que parecem ser os blocos usuais de construção dos discursos falado e escrito) e, por outro, a investigação de tais estruturas é vista como problemática, ficando, em geral, à margem dos estudos lingüísticos (De Cock, 1998, 2002). As fórmulas ou expressões formulaicas - tipo de unidade fraseológica - são unidades multipalavra que desempenham funções estruturais pragmáticas e/ ou discursivas, que, grosso modo, pouco contribuem para o conteúdo proposicional dos enunciados do falante, mas desempenham um importante papel no discurso falado e escrito. (id., 1998: 61).

Desse modo, nosso interesse em estudar esse tipo de fórmula situacional surge, em primeiro lugar, como uma tentativa de compreender por que investigar tais estruturas é visto como problemático - as mesmas acabam ficando à margem dos estudos lingüísticos, como sugere De Cock (2002). Em segundo lugar, nosso interesse originou-se também da escassez de estudos acerca do assunto, sobretudo em lingua portuguesa, bem como da dificuldade de encontrá-las em dicionários de língua portuguesa. Essa combinação de fatores levou-nos, numa primeira etapa, a investigar se tais expressões, típicas da fala, estavam registradas em dicionários de língua portuguesa e, numa segunda etapa, se ocorriam em corpora computadorizados do mesmo idioma.

A propósito, é importante esclarecer que esse interesse por corpora computadorizados advém de nosso recente contato com a Lingüística de Corpus, aqui entendida como uma abordagem que: 
(...) ocupa-se da coleta e da exploração de corpora, ou conjuntos de dados lingüísticos textuais coletados criteriosamente, com o propósito de servirem para a pesquisa de uma língua ou variedade lingüística. Como tal, dedica-se à exploração da linguagem por meio de evidências empíricas, extraidas por computador. (Berber Sardinha, 2004: 3)

Acreditamos que, com o auxílio da Lingüística de Corpus e com o uso de ferramentas adequadas, que permitam o acesso a bancos de dados infinitamente maiores que aqueles anteriores ao advento da computação, possamos realizar um trabalho menos árduo, se comparado a pesquisas em dicionários, por exemplo, que acabam impondo uma análise, além de manual, restrita a uma quantidade limitada de informação. Desse modo, a pesquisa em corpora computadorizados, por meio dessa abordagem, poderá nos ajudar a encontrar as frases feitas jocosas e, assim, validar ou não nossa intuição, visto que as expressões em língua portuguesa [em especial as que se assemelham à descrição de Norrick (1984), explicitada mais adiante] vêm sendo compiladas por nós ao longo de vários anos, exatamente após o contato com o artigo do referido autor. Além disso, acreditamos que, ao partimos de um critério intuitivo e buscarmos por tais expressões em corpora eletrônicos, estamos fazendo um exame em dados reais e, portanto, uma análise da língua efetivamente em uso.

O presente artigo pretende, assim, apresentar um conjunto de fórmulas situacionais, coletadas de maneira intuitiva e, em seguida, buscar - a partir das considerações de Norrick (1984), que define e classifica os stock conversational witticisms (em língua inglesa) e de Tagnin (2005), que discute uma ampla gama de expressões idiomáticas e convencionais - uma denominação, em língua portuguesa, capaz de efetivamente descrever tal ocorrência lingüística, bem como verificar sua ocorrência em dicionários de língua portuguesa: MICHAELIS: moderno dicionário da língua portuguesa (1998); Aurélio Século XXI - O Dicionário da Lingua Portuguesa, de Aurélio Buarque de Holanda Ferreira (1999) e Dicionário Eletrônico Houaiss da Língua Portuguesa (Versão 1.0.5a. Rio de Janeiro: Objetiva, 2001, 1 CD-ROM.), e ainda verificar sua ocorrência em dois corpora eletrônicos de língua 
portuguesa: o Banco de Português, do CEPRIL (Centro de Pesquisa, Recursos e Informação nas áreas de Lingüística Aplicada e Línguas Instrumentais, PUC-SP), ${ }^{1}$ e o Lácio-Ref, corpus de referência público do Projeto Lácio-Web (USP). ${ }^{2}$

Cabe também esclarecer que corpus, para nós, refere-se a:

Um conjunto de dados lingüísticos (pertencentes ao uso oral ou escrito da língua, ou a ambos), sistematizados segundo determinados critérios, suficientemente extensos em amplitude e profundidade, de maneira que sejam representativos da totalidade do uso lingüístico ou de algum de seus âmbitos, dispostos de tal modo que possam ser processados por computador, com a finalidade de propiciar resultados vários e úteis para a descrição e análise. (Sanchez e Cantos, 1996:8-9 apud Berber Sardinha, 2004:18)

\section{A coleta das expressões}

Como informado anteriormente, a compilação das expressões se deu de maneira intuitiva, em virtude de nosso interesse por tais ocorrências há algum tempo. Por exemplo, ao encontrarmos, no artigo de Norrick (1984), as expressões "Is the pope Catholic?" e "Does a bear shit in the woods?", ambas como respostas afirmativas a perguntas aparentemente óbvias, logo nos ocorreu um possivel equivalente em língua portuguesa - "Pergunta se macaco quer banana!", cuja função pragmática nos parece idêntica. A coleta reúne apenas expressões que indicam direta ou indiretamente uma crítica e que sejam capazes de, pelo menos, fazer o interlocutor esboçar um sorriso. De maneira geral, as expressões foram selecionadas considerando a semelhança que poderiam ter com o perfil apresentado por Norrick (1984), ou seja, apresentarem efeito cômico e expressarem uma crítica. Abaixo, encontram-se as 17 expressões que serão analisadas aqui. A tabela apresenta a expressão e indica em que situação ela pode/poderia ser usada.

www2.lael.pucsp.br/corpora/bp/index.htm

www.nilc.icmc.usp.br/lacioweb/ 


\begin{tabular}{|l|l|}
\hline Expressão & Situação em que alguém ... \\
\hline $\begin{array}{l}\text { Cancela o veterinário que o porco está vivo!/ } \\
\text { Suspende a feijoada que o porco está vivo! }\end{array}$ & - arrotou \\
\hline Dormiu com a bunda descoberta? & - está de mau humor \\
\hline É prego ou parafuso? & - está demorando no banheiro \\
\hline Faz o quatro aí, que eu quero ver! & - é suspeito de estar embriagado \\
\hline Filho de vidraceiro! / Espelho sem aço! & - está bloqueando a visão de outra pessoa \\
\hline O gato comeu sua língua? & - não quer falar \\
\hline $\begin{array}{l}\text { Pegou o bonde andando e quer sentar na } \\
\text { janelinha! }\end{array}$ & - chega atrasado e quer ter privilégios \\
\hline Pendura uma melancia no pescoço! & - quer aparecer / se exibir \\
\hline Pergunta se (o) macaco quer banana! & - fez uma pergunta cuja resposta afirmativa é óbvia \\
\hline Que bicho te mordeu? & - está irritado \\
\hline Seu pai é dono / sócio da Light? & - deixou as luzes acesas \\
\hline Tá com formiga na bunda? & - está inquieto \\
\hline Vai ter baile hoje? & - está limpando o nariz \\
\hline Vai tirar o pai da forca? & - está apressado \\
\hline Você não é amendoim, mas torra! & - está incomodando \\
\hline
\end{tabular}

\section{Por que a denominação "frases feitas jocosas"?}

As considerações de Norrick (1984) sobre os stock conversational witticisms e as de Tagnin (2005) sobre as expressões idiomáticas e convencionais contribuíram para nossa decisão de denominar as expressões em estudo de "frases feitas jocosas".

Segundo Norrick (1984), a denominação - stock conversational witticism ("chiste conversacional fixo") - deve-se ao seguinte: witticism ("chiste ou dito espirituoso") refere-se a um enunciado engraçado, que causa riso; conversational (conversacional), além de ser típico da fala, deve ocorrer em conversações em andamento, ou seja, não há indicação de que será usado, nem há interrupção da fala para que seja inserido. Difere, por exemplo, das piadas, que, por meio de determinados marcadores, tais como, "Você conhece a piada do ...?" ou "Você conhece aquela do ...?” são anunciadas; e stock (fixo, usual), por estar armazenado na memória do falante, que o emprega repetidas vezes em situações recorrentes.

Embora já tivéssemos vários elementos para denominar tais combinações, ainda não estávamos satisfeitos e, assim, buscamos mais subsídios em Tagnin (2005).

Segundo a autora, as fórmulas situacionais são "expressões fixas usadas em determinadas ocasiões, quer sejam obri- 
gatórias ou opcionais" e "abrangem desde fórmulas de polidez e de distanciamento, até provérbios, passando por frases feitas, citações e fórmulas de rotina. (ibid., p. 75). Para Tagnin, há três tipos básicos de fórmulas situacionais: as sintáticas, cuja "estrutura é fixa, mas a parte léxica, variável, subdividas em fórmulas de polidez ("Would you mind ...?" / "Você se importaria de ...?") e fórmulas de distanciamento ("It seems that ..." / "Parece que ...") (ibid., p. 77-78); as fórmulas fixas "proferidas a título de comentários dentro de determinada situação", subdivididas em frases feitas ("Act you age!” / "Não seja infantil!”), citações (“To be or not to be, that's the question!" / "Ser ou não ser, eis a questão!", de Shakespeare) e os provérbios ("After a storm comes a calm" / "Depois da tempestade vem a bonança") (ibid., p. 79-82) e, ainda, as fórmulas de rotina, que, mesmo admitindo pequenas variações em sua estrutura, são fixas e ocorrem em situações ritualizadas como, por exemplo, saudações ("Good morning" / "Bom dia"), agradecimentos ("Thank you" / "Obrigado"), desculpas ("Sorry" / "Desculpe"), votos ("Many happy returns of the day" / "Que esta data se repita por muitos anos"), situações alimentares ("Help yourself!" / "Sirva-se!"), entre outras (ibid., p. 82-86).

Interessam-nos, obviamente, as fórmulas fixas, mais especificamente as frases feitas, que, segundo Tagnin, são as fórmulas que, mesmo se as ouvirmos isoladamente, ou seja, fora de contexto, "somos capazes de recriar a situação em que se insere[m]" (ibid., p. 75). Tomemos como exemplo a expressão que aparece no título deste artigo: "Pergunta se macaco quer banana!". O ouvinte (com bastante domínio da língua portuguesa), mesmo sem participar de uma interação, saberá que se trata de uma resposta afirmativa a uma pergunta óbvia. Diante disso, percebemos que as expressões por nós coletadas faziam parte desse grupo. No entanto, ainda possuiam uma característica que as diferenciava das frases feitas em geral e que as aproximavam das apresentadas por Norrick (1984). Daí as expressões aqui estudadas receberem a denominação de frases feitas “jocosas".

Segundo nosso entendimento, tais expressões foram assim denominadas, pois, embora sejam opcionais, estão atrela- 
das a um contexto situacional específico (crítica ou recriminação, por exemplo), sua estrutura é praticamente fixa (há casos de pequenas variações) e são ligeiramente cômicas. Há que se lembrar também de que são altamente idiomáticas, uma vez que o somatório das partes não revela seu sentido e sua aprendizagem se dá pela repetição entre os membros de uma comunidade lingüística, que as emprega com o objetivo de reforçar os elos de amizade e intimidade ou fazer uma crítica, mesmo que tais expressões contenham um vocabulário popular e até mesmo grosseiro, em alguns casos. Segundo Norrick (1984), expressões como essas, mesmo que não empregadas regularmente, são, em geral, conhecidas por todos os membros de uma comunidade lingüística ou, pelo menos, por grupos específicos.

\section{Um pouco mais sobre as frases feitas jocosas}

Em seu artigo, Norrick (1984) descreve os principais tipos de witticisms, apresenta os traços contextuais sintáticos, semânticos e pragmáticos e também analisa o humor característico dessas expressões, bem como o seu aspecto pragmático geral.

Com relação ao aspecto humorístico das expressões por ele apresentadas, Norrick alega que somente é possível agrupálas se considerarmos que o elemento que as une é o conflito de esquemas, ou seja, com base na "teoria da bi-associação do riso" (bisociation theory of laughter), de Koestler (1964, apud Norrick, 1984), ou seja, o humor é criado ao se juntar informação não relacionada e, em geral conflitante, de maneira inusitada. Essa dupla associação consiste na percepção de uma situação ou idéia de duas maneiras consistentes, mas incompativeis - tal percepção dual e simultânea causa o riso. A possivel dupla interpretação está, segundo Norrick, por trás de todos os tipos de expressões agrupados por ele, que aparecem abaixo.

Dessa maneira, o autor classifica os stock conversational witticisms em três categorias principais: comparisons (comparações), retorts (réplicas) e quips (chistes), que, por sua vez, recebem subdivisões. Vejamos cada uma das principais categorias e subdivisões. 
1. Comparisons (comparações): expressões comparativas ou símiles, não necessariamente consagradas ou tradicionais (id., ibid., p. 196):

Ex.: As little chance as a snowball in hell

("Tão improvável quanto uma bola de neve no inferno" = pouca ou nenhuma probabilidade de algo ocorrer ou se realizar com sucesso) ${ }^{3}$

To lie like a rug

("Mentir / Estender-se como um tapete" = mentir descaradamente, sem razão) ${ }^{4}$

Segundo ele, as comparações normalmente apresentam dois elementos comuns e um terceiro, em geral desconhecido, que fará o elo para que a comparação se concretize e produza sentido. No caso dessas expressões, o terceiro elemento distorce o quadro, leva o interlocutor para uma outra interpretação, daí o humor.

2. Retorts (réplicas): expressões que formam um bloco conversacional completo; ocorrem em resposta a um enunciado anterior. Segundo o autor, subdividem-se em punning retorts (réplicas com jogo de palavras), non-punning retorts (réplicas sem jogo de palavras) e evaluative comments (comentários avaliativos) (id., ibid., p. 196-199).

2.1 Punning retorts (réplicas com jogo de palavras): são, em geral, construídas a partir da ambigüidade de um ou mais itens lexicais; dependem, assim, exclusivamente do aspecto lexical.

Ex.: What does your watch say? - Ticktock, ticktock

("O que diz seu relógio? - Tique-taque, tique-taque".)

\section{(Que horas são? - Um pai-nosso e uma ave-maria.)}

Nesse caso, o interlocutor finge uma interpretação diferente de apenas um dos elementos do enunciado, e isso causa o humor: não se esperava tal resposta, há um conflito.

3 Para as frases feitas de Norrick, apresentaremos uma tradução literal, às vezes seguida de uma explicação e, quando possivel, acrescentaremos um suposto equivalente pragmático em lingua portuguesa, em negrito.

4 Aqui, inevitavelmente, o jogo de palavras em português é perdido, uma vez que a expressão conota "mentir descaradamente", tal qual um "tapete fica naturalmente estendido no chão". 
2.2 Non-punning retorts (réplicas sem jogo de palavras): diferentemente da subcategoria anterior, que depende exclusivamente do aspecto lexical para criar a dupla leitura, estas dependem do aspecto semântico. Em geral, o interlocutor finge não compreender o enunciado todo.

Ex.: How old are you? - Old enough to know better (but too young to resist)

("Qual é a sua idade? - Velho(a) o suficiente para saber mais das coisas (porém jovem demais para resistir.")

Nesse exemplo, o interlocutor se esquiva da pergunta indelicada, fingindo não se tratar da idade cronológica, mas sim daquela medida pela experiência e pelo conhecimento. Nesse caso, o humor é criado, pois a resposta entra em conflito com o que se esperava de tal pergunta, indelicada, mas recorrente.

Nessa subcategoria, o autor também inclui as famosas respostas afirmativas óbvias:

Ex.: Are you thirsty? - Is the pope Catholic?

("Você está com sede? - O papa é católico?")

(Você está com sede? - Pergunta se macaco quer banana.)

O humor, aqui, é causado pelo fator surpresa, uma vez que se esperaria um simples "sim" ou "não"; assim, o interlocutor insinua que tal pergunta seria, no mínimo, desnecessária. 2.3 Evaluative comments (comentários avaliativos): expressões que indicam um julgamento de valor acerca do conteúdo da conversa que transcorre.

Ex.: But all seriousness aside now.

("Seriedade à parte.")

Em geral, o humor se dá em conseqüência de sua inserção abrupta, e não pelo humor inerente ou pelo jogo de palavras. O interlocutor, não desejando continuar determinado assunto, sugere sua mudança, ao mesmo tempo em que demonstra seu desagrado.

3. Quips (chistes): segundo Norrick, este tipo de dito espirituoso ocorre como reação a um determinado fato e não está diretamente relacionado a nenhum enunciado anterior, mas sim a uma situação específica. O autor limita esse tipo a três áreas que julga as mais comuns: funções fisiológicas constrangedoras, bloqueio da claridade/visão e entrar/sair de algum lugar. 
3.1 Funções fisiológicas constrangedoras: expressões deste tipo funcionam como uma repreensão pelo fato de o agente ter sucumbido a determinadas funções fisiológicas na presença de outra pessoa. Estão subdivididas em:

3.1.1. Em caso de eructação (arroto):

Ex.: Bring that up again and we'll vote on it.

("Faça de novo que agora a gente vai dar nota.")

(Suspende a feijoada que o porco está vivo.)

3.1.2. Em caso de flatulência:

Ex.: Your voice has changed but your breath still smells the same.

("Sua voz mudou, mas seu bafo continua o mesmo.")

3.1.3. Para alguém que volta do banheiro:

Ex.: Did everything come out all right?

("Saiu tudo bem?")

Nesses casos, fica evidente que as regras de etiqueta e polidez são quebradas e que o interlocutor claramente viola tabus e deseja constranger o outro falante; tanto é que não tenta encobrir o intento - pelo contrário, tece um comentário que se refere exatamente às funções fisiológicas, mas de maneira indireta e, assim, o humor é criado.

1.2. Bloqueio da claridade/visão: expressão que sugere um pedido de licença:

Ex.: You father was no glazier.

("Seu pai não era vidraceiro.")

(Filho de vidraceiro! / Espelho sem aço!)

Nesse caso, o humor se dá pelo comentário em si.

1.3. Ao entrar/sair de algum lugar:

Ex.: Ladies first.

("Primeiro as damas.")

Age before beauty. / Beauty before intelligence.

("Primeiro idade, depois beleza. / Primeiro beleza, depois inteligência.")

A expressão "Ladies first" parece bastante natural; no entanto, torna-se ofensiva quando um homem, ao segurar uma porta, diz isso a outro homem. Já as expressões "Age before beauty./ Beauty before intelligence" demonstram, no minimo, indelicadeza e parecem mais uma provocação do que um sim- 
ples gracejo. No entanto, ao serem empregadas principalmente entre pessoas com um certo grau de intimidade, elas soam engraçadas.

Com relação ao aspecto pragmático geral dessas expressões, Norrick (1984) diz que os falantes armazenam as stock conversational witticisms (SCWs) que se mostraram bem-sucedidas, isto é, que fizeram seus interlocutores rirem e, diante de contextos conversacionais apropriados recorrentes, as reutilizam. Com isso, esperam salientar sua capacidade de conversarem de maneira inteligente e espirituosa, principalmente na presença de seus pares. Dessa maneira, Norrick acredita que sua maior incidência se dê entre amigos, conhecidos, colegas, pessoas com as quais se tem algum contato e que se espera rever. Porém, os falantes devem escolher cuidadosamente as situações em que empregam tais expressões, visto que elas tendem a ignorar determinados tabus e convenções de polidez, indicando, por sua vez, camaradagem em contextos agradáveis e familiares.

O autor salienta a diferença que as SCWs têm se comparadas com outras fórmulas desprovidas de humor, que são geralmente aprendidas em tenra idade, em casa e com os pais. Tais fórmulas (as desprovidas de humor) têm uma função específica: o falante tenta evitar tabus, agindo com tato e demonstrando polidez. São tais habilidades que os falantes precisam desenvolver, principalmente na presença de estranhos e em situações complexas que exigem uma reação (pedido de desculpas, agradecimentos, pêsames etc.). Aí fazemos uso de fórmulas consagradas de maneira habilidosa, não dando motivo para nenhum tipo de constrangimento. Porém, Norrick questiona o seguinte: como as SCWs estão ligadas por polidez e camaradagem se, aparentemente, rompem regras de etiqueta, sinalizam observações ofensivas e violam tabus? (p. 181).

Para o autor, há três possiveis respostas inter-relacionadas: em primeiro lugar, ao empregar tais expressões entre seus pares, o falante demonstra identificação com o grupo, informando que aprecia os mesmos tipos de histórias e piadas. Em segundo, ao lançar por terra regras de etiqueta e polidez, o falante indica ao seu interlocutor que está falando de maneira franca 
com amigos de confiança. As supostas ofensas e a violação de tabus conferem um vínculo de intimidade, pois revelam compreensão mútua. Em terceiro, ao se valer de uma observação engraçada, o falante alivia a tensão que pode haver em algumas situações constrangedoras ou dificeis.

Mas como é resolvido o impasse de se fazer a crítica e ao mesmo tempo preservar princípios de polidez? Acreditamos que a tensão não seja eliminada; ela é apenas atenuada. Por exemplo, quando alguém responde "Pergunta se macaco quer banana!", o falante não está pedindo ao outro que procure um primata e faça tal pergunta; ele está, sim, fazendo uma crítica, pois, independentemente da pergunta que suscitou tal resposta, não havia por que a fazer, por se tratar, segundo nos indica a frase feita jocosa, de uma pergunta cuja resposta afirmativa seria óbvia. Em geral, utilizamos estratégias que atenuam a tensão criada, empregando, na maioria das vezes, expressões convencionalizadas, caracterizadas como fórmulas de rotina (Coulmas, 1979) ou fórmulas situacionais (Tagnin, 2005) que, devido ao seu uso constante e rotineiro, são depreendidas como um todo, facilitando, assim, a conversação e, conseqüentemente, as relações sociais. Desse modo, ao ser criticado por meio de uma frase feita jocosa, o ouvinte/falante é desarmado e aceita a crítica, ignorando a violação dos princípios básicos de polidez. Há que se lembrar, no entanto, de que tais expressões devem ser empregadas entre pessoas com as quais temos certa afinidade e intimidade, pois, ao empregá-las, na hora certa, os falantes demonstram identificação com o grupo, franqueza e confiança entre os amigos. Se empregadas diante de estranhos ou diante de pessoas de graus hierárquicos diferentes, elas estarão, sem dúvida, rompendo regras de polidez e causarão constrangimento.

\section{Classificação das fórmulas jocosas em português brasileiro}

Com relação às frases feitas jocosas aqui estudadas, acreditamos que apenas uma categoria seja suficiente para agrupálas: comentário avaliativo. 
O comentário avaliativo refere-se a situações em que o falante informa que não aprova o comportamento de seu interlocutor. Embora as expressões façam uso de ironia, fica claro que tais atitudes não são bem-vindas. A maioria se enquadra nesta categoria:

Cancela o veterinário que o porco está vivo!/ Suspende a feijoada que o porco está vivo!

Dormiu com a bunda descoberta?

É prego ou parafuso?

Faz o quatro aí, que eu quero ver!

Filho de vidraceiro! / Espelho sem aço!

O gato comeu sua lingua?

Pegou o bonde andando e quer sentar na janelinha!

Pendura uma melancia no pescoço!

Que bicho te mordeu?

Pergunta se macaco quer banana!

Tá com formiga na bunda?

Vai ter baile hoje?

Vai tirar o pai da forca?

Você não é amendoim, mas torra!

Acreditamos que o humor, nessas expressões, ocorra pelo fato de o comentário ser feito de maneira inesperada, salientando algo que não deveria ser notado. Mas como isso é feito por meio de uma expressão aparentemente desvinculada do que acaba de ser feito, o interlocutor entende como uma brincadeira, porém está sendo criticado.

\section{A ocorrência das fórmulas situacionais jocosas em dicionários e em corpora eletrônicos}

Nossa busca em dicionários foi feita no MICHAELIS: moderno dicionário da língua portuguesa (1998); no Aurélio Século XXI - O Dicionário da Língua Portuguesa, de Aurélio Buarque de Holanda Ferreira (1999), e no Dicionário Eletrônico Houaiss da Lingua Portuguesa (2001), que, segundo nossa experiência, são 
publicações recentes e bastante consultadas por nossos alunos e, além disso, são obras de referência da língua portuguesa do Brasil. No entanto, nossa busca em tais dicionários logo se mostrou improdutiva, uma vez que a maioria das expressões por nós coletadas praticamente não foi encontrada ali.

Lembremos ainda que, mesmo quando aparecem, essas unidades não recebem nenhuma indicação de que se trata de uma expressão específica, elas apenas constituem uma expressão popular brasileira, por exemplo. Este é o caso de "pegar o bonde andando", que figura no verbete de "bonde", somente no Aurélio, e que contém a seguinte definição: “(Bras. Pop.) 1. chegar-se a um grupo de pessoas e tomar parte na conversa, sem saber o que ocorreu, ou o que se disse até então; 2. chegar a determinado evento (sessão de cinema, de teatro, conferência, etc.) quando já iniciado." (p. 318). Há que se salientar que a expressão "Pegou o bonde andando e quer sentar na janelinha!", considerada aqui como frase feita jocosa, não aparece na íntegra no dicionário, apenas parcialmente. Desse modo, podemos dizer que, de fato, a expressão não consta do referido dicionário. Já "espelho sem aço", que aparece grafado com hifens, tem verbete próprio, com a seguinte definição: "pessoa que se põe na frente de outra obstruindo-lhe a visão” (p. 814). Igualmente ao verbete da outra expressão, este não traz nenhuma informação adicional a respeito de seu uso ou registro.

Em seguida, fizemos nossa busca nos seguintes corpora eletrônicos: i) Banco de Português ${ }^{5}$ - criado e mantido pelo Prof. Dr. Tony Berber Sardinha, é parte do projeto de Lingüística de Corpus desenvolvido no Departamento de Lingüística Aplicada ao Ensino de Línguas, na PUC-SP. É um corpus monitor ${ }^{6}$ do português do Brasil, atualizado constantemente, que em 2004 contava com 223 milhões de palavras (tokens). O acesso via internet permite consulta a uma amostra do corpus com cerca de 1,1 milhão de palavras. Nossa busca limitou-se aos registros

\footnotetext{
5 www2.lael.pucsp.br/corpora/bp/index.htm

6 Corpus monitor: aquele cuja "composição é reciclada para refletir o estado atual de uma lingua” (Berber Sardinha, 2005: 20).
} 
falados, apenas 197.901 palavras; ii) Lácio- $\operatorname{Ref}^{7}$ - corpus aberto $^{8}$ e de referência ${ }^{9}$ do Projeto Lácio-Web, iniciado em janeiro de 2002 e composto de textos em português brasileiro, tendo como característica serem escritos respeitando a norma culta, elaborado em parceria com o NILC (Núcleo Interinstitucional de Lingüística Computacional), ICMC-USP, o IME (Instituto de Matemática e Estatística) e a FFLCH (Faculdade de Filosofia, Letras e Ciências Humanas), ambos também da Universidade de São Paulo.

Da mesma maneira, nossa busca não foi feliz nesses corpora, pois ambos - o primeiro de aulas e conversação e o segundo de textos escritos, em sua maioria jornalísticos - parecem não ser o ambiente privilegiado das frases feitas jocosas, o que, por sua vez, nos levou a procurá-las na internet. Para tanto, empregamos o buscador Google e a ferramenta KWIC Google - formatador de resultados do buscador Google, recurso disponível na página do CEPRIL (PUC-SP) em Bancos de Dados e Ferramentas de Análise. ${ }^{10} \mathrm{O}$ KWIC Google tem como função transformar uma lista de resultados de busca do Google numa lista de concordância do tipo KWIC (Key Word in Context), em que cada linha traz a palavra ou as palavras de busca centralizada(s) e seu contexto imediato à esquerda e à direita.

\section{A busca das frases feitas jocosas na internet por meio do Google}

Como todas as expressões em questão se caracterizam pela sua fixidez, ou seja, são passiveis de poucas alterações em sua estrutura, todas foram pesquisadas exatamente como supomos que sejam empregadas, embora saibamos que, na busca pelo

\footnotetext{
7 www.nilc.icmc.usp.br/lacioweb/

8 Corpus aberto: aquele que aceita adaptações ou reajustes quanto à inserção ou remoção de dados.

9 Corpus de referência: aquele "usado para fins de contraste com o corpus de estudo.” (Berber Sardinha, 2005: 21)

10 www2.lael.pucsp.br/corpora/google/index.html www2.lael.pucsp.br/ corpora/bp/index.htm
} 
Google, não há a necessidade de incluirmos palavras funcionais. De qualquer maneira, essa foi nossa primeira tentativa de busca. Dessa forma, todas as expressões foram digitadas na íntegra e entre aspas - este é o recurso por meio do qual o buscador recupera a palavra ou expressão exatamente como digitada na janela de busca.

Para elucidarmos como nossa busca foi feita, tomemos como exemplo a expressão "Suspende a feijoada que o porco está vivo".

Em primeiro lugar, então, inserimos a fórmula na íntegra e entre aspas na janela de busca do Google. O resultado obtido foi:

Web Resultados 1 - $\mathbf{1}$ de $\mathbf{1}$ para "Suspende a feijoada que o porco está vivo" (0,43 segundos)

Fórum - Individualidade

... Suspende a feijoada que o porco está vivo !" Ah ! Ah ! Valeu !!!!! Ganhei o dia!

Meu abraço Renata A. [ Voltar para página principal do Fórum ] ... www.individualidade.com. br/forum/vermsg.asp?id=246 - 5k

Sabemos que, mesmo diante do alto grau de fixidez, outras variações poderiam ocorrer. Precisávamos, então, nos certificar de que pudesse haver outras maneiras de representá-la. Procedemos, assim, a uma nova busca, indicando apenas as palavras que acreditamos sejam as palavras-chave: suspende feijoada porco vivo. Os resultados dessa nova busca foram:

Web Resultados $\mathbf{1}$ - $\mathbf{1 5}$ de aproximadamente $\mathbf{1 6}$ para suspende feijoada porco vivo $(0,30$ segundos $)$

Sem título

... SUSPENDE A FEIJOAdA QUE O MONTOIA TÁ VIVO!!! ... Agora o Porco é da maclaren, vc verão a lambança que ele vai fazer lá. KKKKKKKKKKKKKKKKKKKK $\cdots$ www.supergp.com.br/super-imagem.asp - 32k

Fórum - Individualidade

... Suspende a feijoada que o porco está vivo !" Ah ! Ah ! Valeu !!!!! Ganhei o dia! 
Meu abraço Renata A. [ Voltar para página principal do Fórum ] ... www.individualidade.com. br/forum/vermsg.asp?id=246 - 5k

Concurso escolhe maior arroto

... Então, nada de gracinhas (do tipo: suspende a feijoada que o porco tá vivo!).

O lance é encher o pulmão e fazer o maior barulho. SERVIÇO. ... www.dpnet.com.br/anteriores/1998/03/20/viver11_0.html - 8k

Parlapatões, Patifes e Paspalhões

... Ou pra dizer que a comida esteve perfeita. (Claudinei arrota) Kinojo: Ô Jorjão!

Suspende a feijoada que o porco tá vivo! (sai). Texto de Mário Viana. www2.uol.com.br/parlapatoes/ espetaculos/r_1chopes/tr.htm - 5k

Mim quer falar!!!

... Pra evitar comentários babacas, do tipo: "tá gordinho, meu filho, hein?" "suspende a feijoada, qo porco ainda tá vivo!" "bota isso aí aki na minha mão, q ...

raphapontog.blogspot.com/2003_01_01_raphapontog_archive.html $101 \mathrm{k}$

macunaima

... informativo - Macunaíma, apavorado, corre perigo de cair na feijoada do gigante.

... sobrevoa a feijoada de carne humana, tendo ao fundo o embaixador, ...

www.pacc.ufrj.br/heloisa/macunaima.html - 187k

blowg: marco 2002 Archives

... você também encontra lugares onde você pode comer feijoada e tomar caipirinha.

... prazeres era cozinhar para os amigos: arroz, feijão, carne de porco.

...

www.blowg.pixelzine.com/archives/2002_03.html - 101k

Agronet

... Coreanos aprendem a fazer feijoada para aos brasileiros Fazendeiro oferece colheita de arroz à ... Ibama suspende concessão para criadouros de répteis ...

www.agronet.com.br/cgi-bin/artigos.pl?m=052002 - 513k

\section{Just a Point of View}

... R: Sim, é possível que ele estivesse vivo e exercendo Direito em Algum lugar!! 
... 5 - Vatapá, feijoada, tutu de feijão, moqueca capixaba, ... www.hackhour.com.br/blog/index.php?blogid=1\&archive=2002-10 $-278 \mathrm{k}$

\section{**NOSSO AMOR DE ONTEM**}

... onde simplesmente nÃ£o hÃ $\tilde{A}_{i}$ como distinguir o que est $\tilde{A}_{i}$ vivo do que nÃ£o est $\tilde{A}_{i}$.

... eo porco est $\tilde{A}_{i}$ comprometido numa feijoada porque se d $\tilde{A}_{i}$ inteiro, ... nossoamordeontem.weblogger.terra.com.br/200408_nossoamorde ontem_arquivo.htm - 444k

\section{LegislacaoGeral}

... Gorduras e Óleos Gordos (Azeite, banha e outras gorduras de porco); ...

de refeições prontas para consumo - Ex.: enlatado de feijoada à transmontana...) ...

www.hisa.pt/InforHisa/LegislacaoGeral.htm - 263k

\section{[RTF] PEGAR TANAJURA}

Formato do arquivo: Rich Text Format - Ver em HTML

... e só levantarão quando o perseguido, já afastado do grupo, gritar: "Vivo"!

... Faz-se bolo, pastel, carne de porco, usando terra, semente, flores, ... www.nepsid.com.br/brincadeiras/estados/rj.rtf

\section{PAGINA DA KARIN}

... e do sul dos Estados Unidos, região que prepara não só torresmos, como também a feijoada. ... mas no Ratinho, numa comparação grotesca com um porco. ...

paginadakarin.blogspot.com/ - 154k

a á à ã aacho aacute abacaxi abade abaeté abafar abafaram abaixa ... ... feição feições feijão feijó feijoada feio feios feira feirante feiras feita ... suspeito suspeitos suspeitou suspende suspendendo suspender suspenderiam ...

snowball.tartarus.org/portuguese/voc.txt $-282 \mathrm{k}$

\section{[RTF] SONHOS D'OURO}

Formato do arquivo: Rich Text Format - Ver em HTML

... Galgo" eo formoso isabel também se cortejaram: o cavalo brasileiro, vivo, ardente e ... ele costuma dormir duas horas, e três quando janta feijoada; portanto aí ...

www.sitedoescritor.com.br/sitedoescritor_escritores_jalencar_texto 011.rtf 
Como podemos observar, os resultados, além de incluírem a única ocorrência da outra busca (expressão na integra e entre aspas), apresentam várias ocorrências que nos interessam e uma série de outras que não, pois as palavras-chave expandem a gama de combinações entre si e, conseqüentemente, nem todas constituem a expressão desejada. Então, se a busca com as palavras-chave inclui o único resultado da busca com a expressão na întegra e entre aspas, por que não realizar apenas a busca com as palavras-chave? Porque veremos, mais adiante, que algumas expressões foram encontradas apenas quando digitadas na întegra e entre aspas (por exemplo, "Você não é amendoim, mas torra.").

Em seguida, ocorreu-nos que a expressão também poderia ser empregada de outras maneiras, como, por exemplo: "Suspenda a feijoada que o porco está vivo" ou "Vamos suspender a feijoada que o porco está vivo". Porém, para "suspenda feijoada porco vivo", não encontramos nenhuma ocorrência. E, para "suspender feijoada porco vivo", houve aproximadamente 24 ocorrências, mas nenhuma que apresentasse a expressão propriamente dita, apenas ocorrências em que as palavras-chave apareciam sem constituir uma frase feita.

Em seguida, as 16 ocorrências da busca "suspende feijoada porco vivo" foram analisadas na ferramenta KWIC Google, formatador de resultados do buscador Google (Bancos de Dados e Ferramentas de Análise, do CEPRIL, PUC-SP). Escolhemos como nódulo a palavra "feijoada", e os seguintes alinhamentos foram apresentados: 


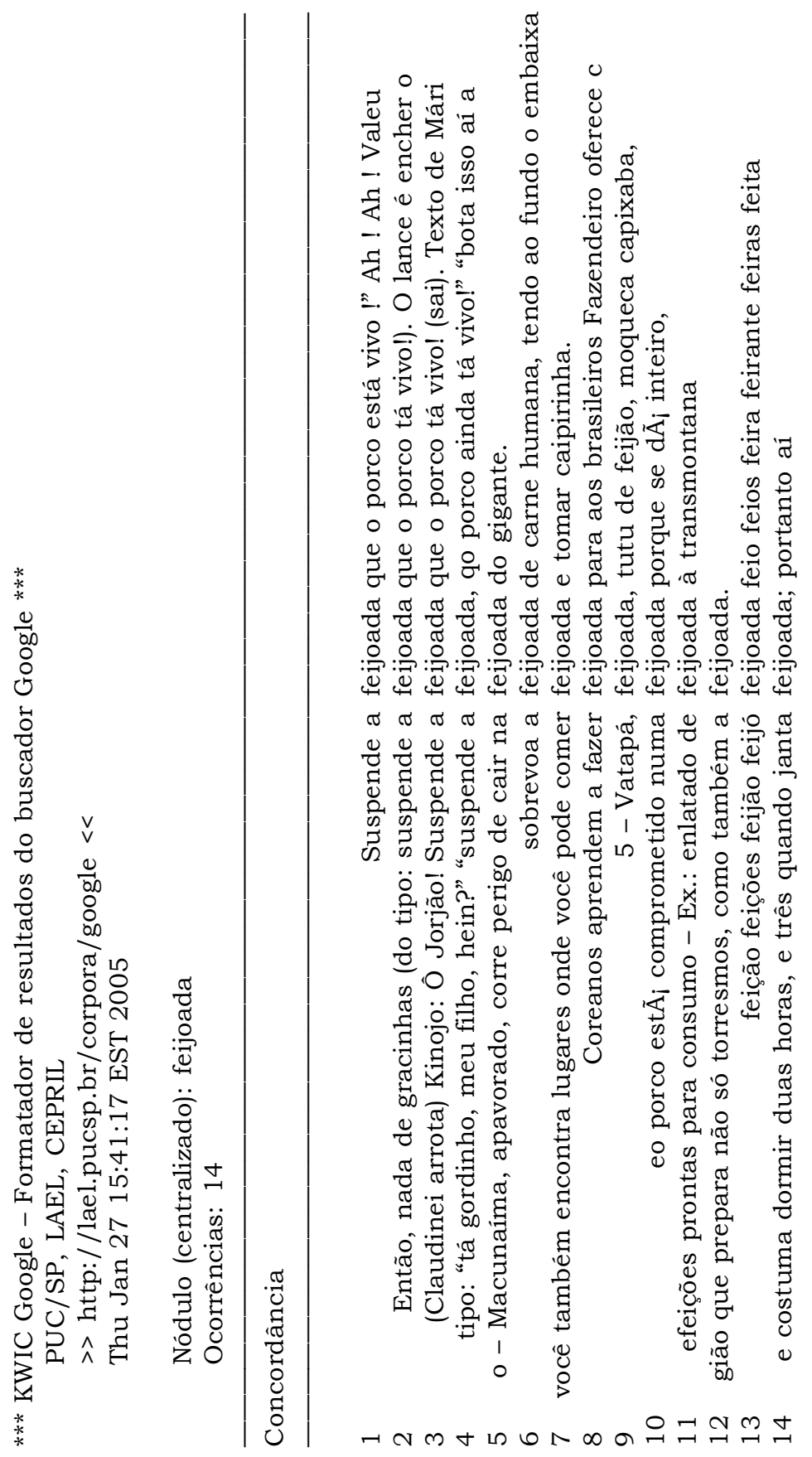

TradTERM, 12, 2006, p. 127-157 
Para nossa análise quantitativa, obviamente, apenas os resultados que, de alguma forma, nos remetiam à expressão foram considerados, ou seja, apenas os quatro primeiros:

1. Suspende a feijoada que o porco está vivo!

2. suspende a feijoada que o porco tá vivo!

3. Suspende a feijoada que o porco tá vivo!

4. suspende a feijoada, qo porco ainda tá vivo!

Com isso, podemos notar que a expressão, tal qual a supomos conhecer (Suspende a feijoada que o porco está vivo), foi encontrada com pequenas alterações em sua forma. Por exemplo, com uma redução do verbo, de "está" para "tá", ocorrência escrita que conota uma preocupação em representar traços da oralidade, dimensão em que tal expressão é mais freqüente (exemplos 2 e 3, acima). Além dessa, uma ocorrência com alterações ligadas ao meio eletrônico, cuja ortografia se revela cada vez mais "telegráfica", a ponto de "que o" se transformar em "qo", que, do ponto de vista fonológico, se equivalem, não comprometendo o grau de inteligibilidade. A mesma ocorrência inclui a conjunção "ainda" (exemplo 4, acima).

Seguindo critérios semelhantes de busca, as demais expressões foram procuradas. A tabela abaixo inclui, assim: i) a expressão e as palavras de busca (entre aspas), ii) as ocorrências em função da busca com diferentes palavras-chave, iii) o número de ocorrências após a "triagem" feita por meio da ferramenta KWIC Google (CEPRIL, PUC-SP) e iv) o total de ocorrências.

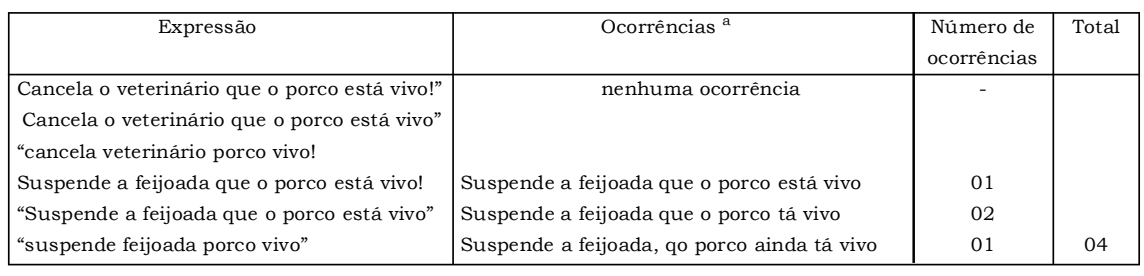

a Nesta coluna, as ocorrências aparecem sem nenhum tipo de edição, ou seja, estão exatamente como foram grafadas nos sites. 


\begin{tabular}{|c|c|c|c|}
\hline $\begin{array}{l}\text { Dormiu com a bunda descoberta? } \\
\text { "Dormiu com a bunda descoberta?" } \\
\text { "dormiu bunda descoberta" }\end{array}$ & $\begin{array}{l}\text { Dormiu com a bunda descoberta. } \\
\text { Dormiu com a bunda descoberta? } \\
\text { Dormiu com a bunda descoberta, foi? } \\
\text { Nossa, parece até que dormiu com a bunda } \\
\text { descoberta! } \\
\text { Vc durmiu com a bunda descoberta essa } \\
\text { noite? }\end{array}$ & $\begin{array}{l}02 \\
01 \\
01 \\
01 \\
01\end{array}$ & 06 \\
\hline $\begin{array}{l}\text { É prego ou parafuso? } \\
\text { "É prego ou parafuso?" } \\
\text { "prego parafuso" }\end{array}$ & nenhuma ocorrência & - & - \\
\hline $\begin{array}{l}\text { Espelho sem aço! } \\
\text { "Espelho sem aço!" } \\
\text { "espelho aço" } \\
\text { Filho de vidraceiro! } \\
\text { "Filho de vidraceiro!" } \\
\text { "filho vidraceiro" }\end{array}$ & $\begin{array}{l}\text { Sai da frente, espelho sem aço. } \\
\text { Você é filho de vidraceiro? }\end{array}$ & 02 & 03 \\
\hline $\begin{array}{l}\text { Faz o quatro aí que eu quero ver! } \\
\text { "Faz o quatro aí que eu quero ver!" } \\
\text { "faz o quatro" } \\
\text { "faz um quatro" } \\
\text { "fazer o quatro" } \\
\text { "fazer um quatro" } \\
\text { "fez o quatro" } \\
\text { "fez um quatro" }\end{array}$ & 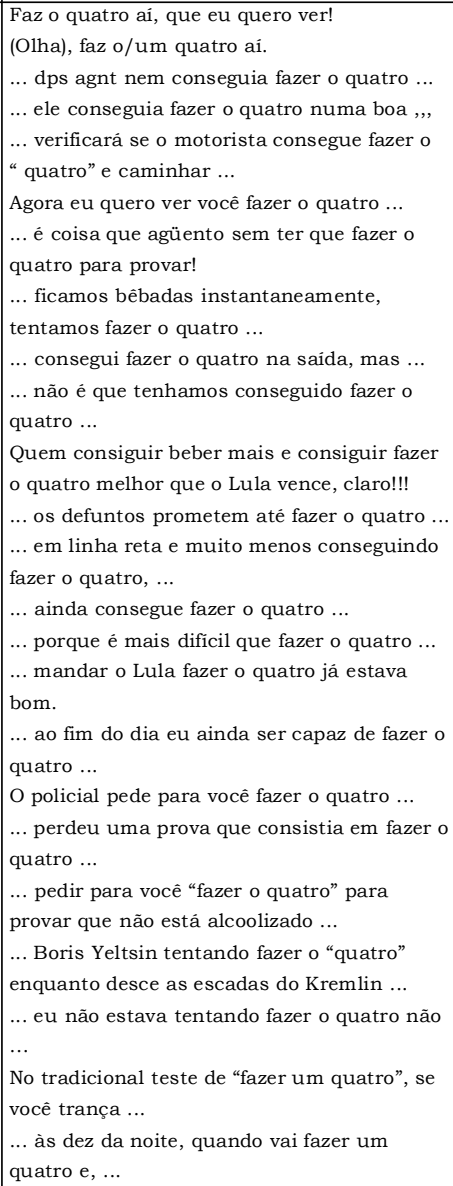 & 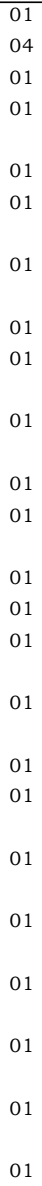 & \\
\hline
\end{tabular}




\begin{tabular}{|c|c|c|c|}
\hline & 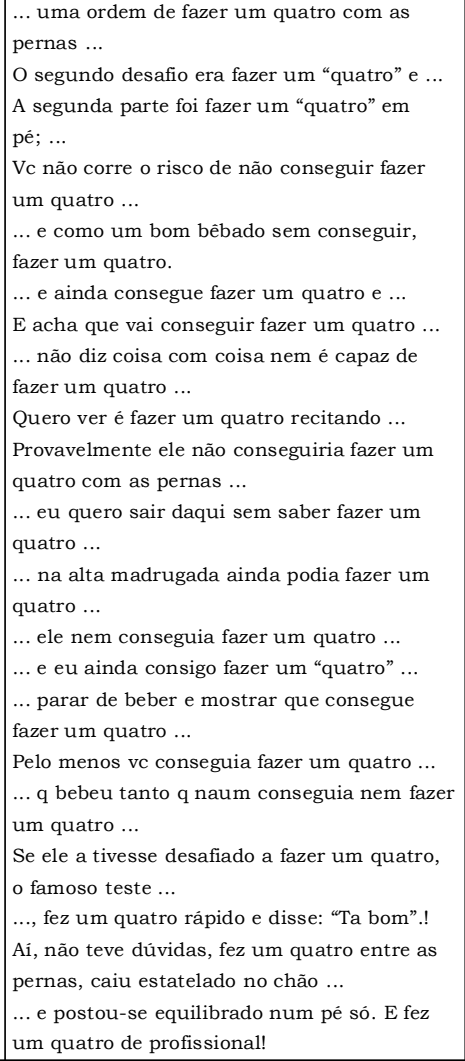 & $\begin{array}{l}01 \\
01 \\
01 \\
01 \\
01 \\
01 \\
01 \\
01 \\
01 \\
01\end{array}$ & 48 \\
\hline $\begin{array}{l}\text { O gato comeu sua língua?" } \\
\text { "O gato comeu sua língua?" } \\
\text { "gato comeu língua" }\end{array}$ & $\begin{array}{l}\text { O gato comeu a lingua? } \\
\text { O gato comeu a sua lingua? } \\
\text { O gato comeu sua língua? } \\
\text { O gato comeu a minha língua! } \\
\text { Parece que o gato comeu sua língua! } \\
\text { Será que o gato comeu a língua dele? } \\
\text { Um gato comeu sua língua? }\end{array}$ & $\begin{array}{c}- \\
04 \\
14 \\
01 \\
01 \\
01 \\
01 \\
\end{array}$ & 22 \\
\hline $\begin{array}{l}\text { Pegou o bonde andando e quer sentar } \\
\text { na janelinha! } \\
\text { "Pegou o bonde andando e quer sentar } \\
\text { na janelinha!" } \\
\text { "bonde andando sentar janelinha" }\end{array}$ & $\begin{array}{l}\text { Não dá para entrar no bonde andando e já } \\
\text { sentar na janelinha. } \\
\text {... quer pegar o bonde andando e "sentar na } \\
\text { janelinha", } \\
\text { Pega o bonde andando e quer sentar na } \\
\text { janelinha! } \\
\text { Peguei o bonde andando e quis sentar na } \\
\text { janelinha! } \\
\text { A senhora pegou o bonde andando e quer } \\
\text { sentar na janelinha! } \\
\text {... fica pegando o bonde andando e quer } \\
\text { sentar na janelinha, } \\
\text { Pegou o bonde andando e (agora/ainda) quer/ } \\
\text { quis sentar na janelinha! }\end{array}$ & $\begin{array}{l}06 \\
01 \\
01\end{array}$ & \\
\hline
\end{tabular}

TradTerm, 12, 2006, p. 127-157 


\begin{tabular}{|c|c|c|c|}
\hline & 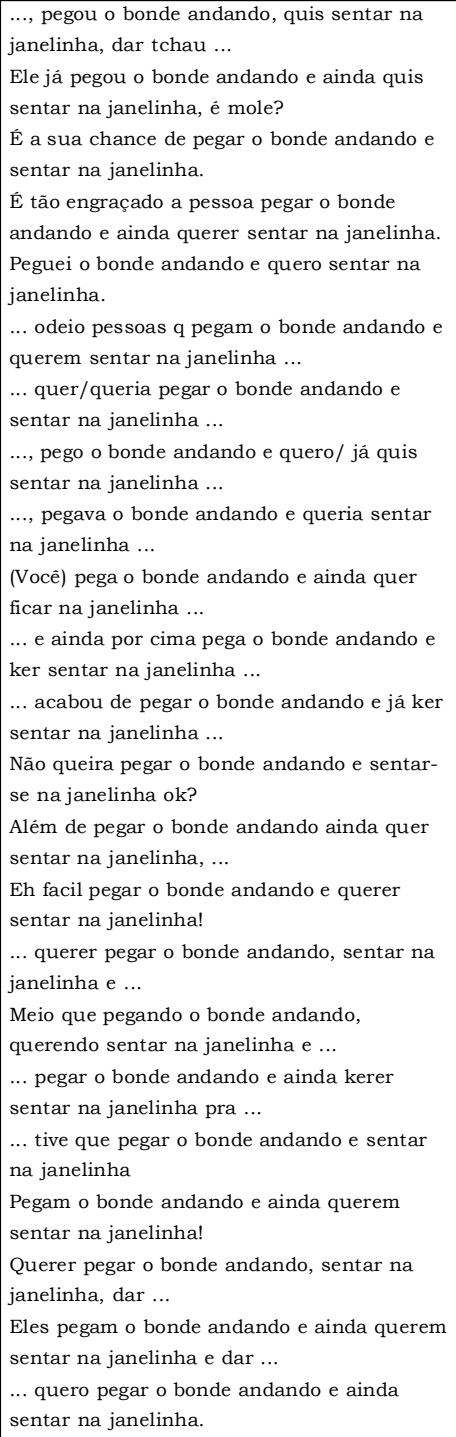 & $\begin{array}{l}01 \\
05 \\
02 \\
01 \\
03\end{array}$ & 50 \\
\hline $\begin{array}{l}\text { Pendura uma melancia no pescoço! } \\
\text { "Pendura uma melancia no pescoço!" } \\
\text { "pendura melancia pescoço" }\end{array}$ & $\begin{array}{l}\text { Quer chamar atenção, pendura uma melancia } \\
\text { no pescoço e ... } \\
\text { Pendura uma melancia no pescoço, nêga. } \\
\text { C vc quer aparecer, pendura uma melancia } \\
\text { no pescoço! } \\
\text { Você quer chamar a atenção? Então pendura } \\
\text { uma melancia no pescoço! } \\
\text { Quer aparecer(,) pendura uma melancia no } \\
\text { pescoço! }\end{array}$ & $\begin{array}{l}03 \\
01 \\
01 \\
02 \\
04\end{array}$ & \\
\hline
\end{tabular}




\begin{tabular}{|c|c|c|c|}
\hline & $\begin{array}{l}\text {... nem precisa dizer anda pendura uma } \\
\text { melancia no pescoço e ... } \\
\text {... para aparecer "neguinho" pendura até } \\
\text { uma melancia no pescoço. } \\
\text { Quer pagar de gatão, pendura uma melancia } \\
\text { no pescoço! } \\
\text { Pendura uma melancia no pescoço! } \\
\text { Quer aparecer? Pendura uma melancia no } \\
\text { pescoço! } \\
\text { Vc quer aparecer, pendura uma melancia no } \\
\text { pescoço e ... } \\
\text { Se quer mesmo aparecer, por que não } \\
\text { pendura uma melancia no pescoço? } \\
\text { Se quer chamar a atenção, pendura uma } \\
\text { melancia no pescoço e ... }\end{array}$ & $\begin{array}{l}01 \\
01 \\
05 \\
02 \\
01\end{array}$ & 24 \\
\hline $\begin{array}{l}\text { Pergunta se o macaco quer banana! } \\
\text { "Pergunta se o macaco quer banana!" } \\
\text { "pergunta macaco quer banana" }\end{array}$ & $\begin{array}{l}\text { Pergunta se macaco quer banana. } \\
\text { Perguntar se macaco quer banana. } \\
\text { Vc pergunta se macaco quer banana!!!! } \\
\text { (risos) } \\
\text { Pergunta se o macaco quer banana? } \\
\text { Pô meu, perguntar pra macaco se quer } \\
\text { banana! } \\
\text { O mesmo que perguntar se macaco quer } \\
\text { banana ... } \\
\text {... tá perguntando se macaco quer banana né } \\
\text {... } \\
\ldots \text {... bahhhhhh ta perguntandu c macaco quer } \\
\text { banana ... } \\
\text { Foi o mesmo que perguntar 'macaco, quer } \\
\text { banana?' }\end{array}$ & $\begin{array}{l}09 \\
01 \\
01 \\
01\end{array}$ & 17 \\
\hline $\begin{array}{l}\text { Que bicho te mordeu? } \\
\text { "Que bicho te mordeu?" } \\
\text { "bicho te mordeu" } \\
\text { "bicho mordeu" } \\
\text { "bixo te mordeu" } \\
\text { "bixo mordeu" }\end{array}$ & $\begin{array}{l}\text { Que bicho te mordeu (aí na lua)? } \\
\text { Até parece/Na sê/Não se sabe/Não sei/Nem } \\
\text { sei/Sei lá que bicho te mordeu ... } \\
\text { Ei ..., que bicho te mordeu? } \\
\text { (Escuta/Diga para mim/Entaõ/Mas/O que } \\
\text { há,) (Q/q)ue bicho te mordeu, (desta } \\
\text { vez/hein/menino)? } \\
\ldots \text {.. (nossa/ora vamos lá ver) que bicho te } \\
\text { mordeu ... } \\
\text { Mas onde o bicho te mordeu? } \\
\text { Que bicho mordeu ...? } \\
\text { Que/q. bixo te mordeu? } \\
\text { Que bixo mordeu ...? } \\
\text {... algum bixo te mordeu ... }\end{array}$ & $\begin{array}{l}90 \\
02 \\
01 \\
30 \\
06 \\
02 \\
01\end{array}$ & 140 \\
\hline $\begin{array}{l}\text { Seu pai é dono da Light? } \\
\text { "Seu pai é dono da Light?" } \\
\text { "pai dono Light" } \\
\text { Seu pai é sócio da Light? } \\
\text { "Seu pai é sócio da Light?" } \\
\text { "pai sócio Light" } \\
\text { "sócio Light" }\end{array}$ & $\begin{array}{l}\text { Apaga/Desliga a/essa luz que a gente não é } \\
\text { sócio da Light! } \\
\text { Apaga isso moleque, que eu não sou sócio da } \\
\text { Light! } \\
\text { Pô, eu não sou sócio da Light! }\end{array}$ & $\begin{array}{l}01 \\
01\end{array}$ & \\
\hline
\end{tabular}

TradTerm, 12, 2006, p. 127-157 


\begin{tabular}{|c|c|c|c|}
\hline & $\begin{array}{l}\text { Não sou sócio da Light! } \\
\text { Você não é sócio da Light! } \\
\text { Você é sócio da Light? } \\
\text { Você pensa/Ta pensando que eu sou sócio da } \\
\text { Light? }\end{array}$ & $\begin{array}{l}04 \\
01 \\
02 \\
03\end{array}$ & 15 \\
\hline $\begin{array}{l}\text { Tá com formiga na bunda? } \\
\text { "Tá com formiga na bunda?" } \\
\text { "formiga na bunda" }\end{array}$ & $\begin{array}{l}\text { Parece (ateh) que tem formiga na bunda } \\
\text { Acho que ele tem formiga na bunda! } \\
\text { Parece que vc tem formiga na bunda, vc não } \\
\text { para no lugar } \\
\text { até parece q tem/tenho formiga na bunda } \\
\text { Parecia que (infeliz) tinha formiga na bunda } \\
\text { Parecia que eu tava com formiga na bunda } \\
\text {... devia estar com "formiga na bunda" } \\
\text { Eu devo ter nascido com formiga na bunda }\end{array}$ & $\begin{array}{l}04 \\
01 \\
01 \\
01 \\
02 \\
02 \\
01 \\
01 \\
01\end{array}$ & 14 \\
\hline $\begin{array}{l}\text { Vai ter baile hoje?" } \\
\text { "Vai ter baile hoje?" } \\
\text { Vai tirar o pai da forca?" } \\
\text { Vai tirar o pai da forca? } \\
\text { "tirar pai forca" }\end{array}$ & $\begin{array}{l}\text { nenhuma ocorrência } \\
\text { (O Senhor) Vai tirar o pai da forca? } \\
\text { Tu não vai tirar o pai da forca, vai? } \\
\text { Parece/ parecendo que vai tirar o pai da } \\
\text { forca! } \\
\text { Vai tirar o pai da forca, vai? } \\
\text {... com a pressa/num ritmo digno/com cara } \\
\text { de quem vai tirar o pai da forca ... } \\
\text { Esse ai vai tirar o pai da forca. } \\
\text { Sempre com pressa. Vai tirar o pai da forca, } \\
\text { é? }\end{array}$ & $\begin{array}{l}- \\
08 \\
01 \\
06 \\
01 \\
03 \\
01 \\
01\end{array}$ & - \\
\hline
\end{tabular}

É possivel notar também que algumas frases feitas não apareceram em nossa busca como as supomos, por exemplo, "Seu pai é dono / sócio da Light?" e "Tá com formiga na bunda?". No entanto, nossa busca revelou expressões bem parecidas, que passam a mesma idéia, como, "Você é sócio da Light?" e "Parece que tem formiga na bunda!", respectivamente.

Além disso, nossa pesquisa demonstra que a maioria das frases feitas jocosas por nós estudadas não apresentam um elevado grau de fixidez, o que, segundo nossa compreensão, não as descaracteriza como tal, apenas sinaliza que, mesmo em se tratando de expressões fixas e consagradas, elas sofrem alterações ao longo do tempo, acompanhando, de certa maneira, uma das características mais marcantes das linguas - o dinamismo - e, portanto, estão em constante mutação, ainda que os itens lexicais e sua ordem na frase se mantenham.

Podemos notar também que as expressões mais usadas são as mais produtivas, o que parece reforçar a idéia de plastici- 
dade das línguas. Isso pode ser ilustrado com a expressão "Pegou o bonde andando e quer sentar na janelinha", que, segundo nossos resultados, foi a que mais mostrou alterações e inovações. Além de uma gama variada de combinações de tempos verbais, ela recebe outros complementos, o que a torna ainda mais peculiar. Vejamos o que foi encontrado:

- Além de pegar o bonde andando, quer sentar na janelinha, ser o maquinista ...

- Meio que pegando o bonde andando, sentar na janelinha e tomar suco ...

- Pega o bonde andando e ainda quer sentar na janelinha dando adeusinho ...

- Pegam o bonde andando e querem sentar na janelinha para dar tchau ...

- Pegou o bonde andando, quis sentar na janelinha, dar tchau para quem ficou na estação ...

- ... querer pegar o bonde andando, sentar na janelinha e dar tchauzinho ...

- Querer pegar o bonde andando, sentar na janelinha, dar tchau para o cobrador e conversar com a velhinha ...

\section{Considerações finais}

Não há como discordar de De Cock (2002): investigar certos tipos de estruturas fraseológicas, tais como as frases feitas jocosas, é, de certa forma, realmente problemático. Acreditamos que uma das razões seja a dificuldade de encontrar registros de sua ocorrência, por serem inesperadas e típicas de conversações coloquiais. Por conseguinte, há escassez de material que as contenha, haja vista, por exemplo, a ausência das várias expressões em dicionários e corpora eletrônicos de língua portuguesa, sobretudo do Brasil.

Além disso, acreditamos que designar tais expressões como frases feitas jocosas parece adequado, uma vez que, embora sejam opcionais em uma conversação, estão atreladas a um contexto situacional específico (crítica ou recriminação), têm uma 
estrutura razoavelmente fixa e são, de certa maneira, engraçadas. Há que se lembrar também que são altamente idiomáticas: o somatório das partes não revela seu sentido e sua aprendizagem se dá pela repetição entre os membros de uma comunidade lingüística, que as emprega com o objetivo de reforçar os elos de amizade e intimidade ou fazer uma crítica, mesmo que, em alguns casos, contenham um vocabulário popular e até mesmo grosseiro. Além disso, mesmo que não sejam empregadas regularmente, as frases feitas jocosas são conhecidas por certos grupos de uma comunidade lingüística, muitas vezes frutos de usos regionais ou até mesmo familiares.

Com relação à ocorrência das frases feitas jocosas em dicionários, ficou evidente que tais eventos lingüísticos ainda não fazem parte de seu repertório. Embora houvéssemos imaginado que muitas das expressões estivessem nos dicionários, sua ausência revela que os produtos lexicográficos analisados não registram certos usos e costumes da língua, fato a ser lamentado, uma vez que, possivelmente, essas expressões, ditos e outras manifestações lingüísticas, típicos da cultura brasileira, poderão cair no esquecimento. Desse modo, cabe a lexicógrafos dedicarem mais atenção a essas ocorrências e a incluírem-nas em suas obras.

Acreditávamos que a consulta a corpora eletrônicos, por compilarem uma quantidade bem maior de informações e por serem atualizados com mais freqüência, pudesse apresentar resultados mais satisfatórios. No entanto, constatamos que as expressões aqui estudadas fazem parte de uma "língua falada" que ainda não foi documentada, pelo menos, nos dois corpora pesquisados. Com isso, mostram-se inadequados para o tipo de investigação aqui proposto. Por outro lado, a internet, com sua ampla gama de textos em sites nem sempre construídos segundo rigorosos critérios de qualidade e confiabilidade, mostrou-se capaz de fornecer material adequado e suficiente para o nosso propósito. Salientamos que, dentre os vários tipos de sites, os blogs e os fóruns foram responsáveis por 32\% das ocorrências. Acreditamos que isso tenha ocorrido pelo fato de os blogs e os fóruns serem compostos por pequenos parágrafos, com conteúdo que inclui uma ampla gama de assuntos, tais como diários, 
piadas, links, notícias, poesia, idéias, fotografias etc., que atuam como excelentes formas de comunicação entre familiares, amigos, grupos de trabalho, ou até mesmo empresas, permitindo, assim, que os participantes se comuniquem de forma simples, como se estivessem conversando. A partir disso, acreditamos que sejam fontes de pesquisa adequadas para coleta de materiais que representem a língua falada. Deixamos aqui a sugestão de que corpora elaborados exclusivamente a partir de blogs e fóruns possam ser bastante úteis para a análise de expressões situacionais, fórmulas de rotina, frases feitas, entre outras.

Finalizando, reiteramos o fato de que, embora tenha aumentado o número de estudos sobre as estruturas pré-fabricadas nas últimas décadas, é necessário que mais pesquisa sobre as frases feitas jocosas e outras expressões formulaicas, sobretudo em lingua portuguesa, seja realizada, com o propósito de auxiliar não apenas aprendizes dessa língua, mas também aqueles que realizam trabalhos de tradução nesse idioma, quer como língua de partida ou de chegada. Em face disso, sentimo-nos motivados a, num futuro próximo, dar continuidade à pesquisa, por meio da criação de corpora a partir de blogs, e expandir a análise para o português europeu e o inglês americano, com o objetivo de fornecer, assim, subsídios tanto para o ensino como para a tradução dessas línguas.

\section{Referências bibliográficas}

ARAÚJO, J.P. Invisivel, Oculta ou Profunda? - A Web que poucas ferramentas enxergam. [Online] Disponivel em: <www.comunicar.pro.br/ artigos/weboculta.htm> 2001. Consulta em: 26 de julho de 2004.

BERBER SARDINHA, Tony. (2004) Lingüística de Corpus. São Paulo: Manole.

BIBER, Douglas; CONRAD, Susan \& REPPEN, Randi. (1996) CorpusBased Investigations of Language Use. In: Annual Review of Applied Linguistics, 16, New York: Cambridge University Press, p. 115-136. COULMAS, F. (1979) On the Sociolinguistic Relevance of Routine

Formulae. In: Journal of Pragmatics. vol. 3, [S.1.: s.n.] p. 239-266. De COCK, Sylvie. (2002) Pragmatic Prefabs in Learners' Dictionaries. In: Braasch, A. \& Polvsen, C. (eds.) Proceedings of the Tenth EURALEX 
International Congress, Copenhagen, Denmark, August 13-17, vol. II, Center for Sprogteknologi, p. 471-481.

. (1998) A Recurrent Word Combination Approach to the Study of Formulae in the Speech of Native and Non-Native Speakers of English. In: International Journal of Corpus Linguistics, vol. 3(1), p. 59-80.

DICIONÁRIO ELETRÔNICO HOUAISS DA LÍNGUA PORTUGUESA. (2001) Rio de Janeiro: Objetiva.

FERREIRA, Aurélio Buarque de Holanda. (1999) Aurélio Século XXI-O Dicionário da Língua Portuguesa. Rio de Janeiro: Nova Fronteira.

MICHAELIS: Moderno dicionário da língua portuguesa. (1998) São Paulo: Companhia Melhoramentos.

O QUE É BLOGGER? [Online] Disponivel em: < http://blogger.globo. com/br/about.jsp> 2004. Consulta em: 4 de fevereiro de 2005.

ROBB, Thomas. Google as a Corpus Tool? [Online] Disponivel em : http:/ /www.kyoto-su.ac.jp/ trobb/googleAsConc.html> 2003. Consulta em: 28 de julho de 2004.

TAGNIN, S. E. O. (2005) O jeito que a gente diz- Expressões convencionais e idiomáticas - inglês e português, São Paulo: Disal. 